\title{
PERANCANGAN REPOSITORI ARSIP DIGITAL ISTANA SIAK
}

\author{
Nining Sudiar*), Iik Idayanti**), Rosman H.***) \\ Universitas Lancang Kuning, Riau, Indonesia \\ email: sudiar.nining@gmail.com*), idayanti.iik@gmail.com**), \\ rosmanpanam@gmail.com***)
}

Naskah diterima: 30 Desember 2019; direvisi: 20 Januari 2020; disetujui: 28 Januari 2020

\begin{abstract}
Abstrak
Arsip digital yang menjadi objek penelitian ini adalah arsip peninggalan Sultan Syarif Qasim II yang memerintah pada periode 1915-1946. Seluruh arsip berjumlah kurang lebih 60 ribu, dan sebagian besar arsip sudah direstorasi serta didigatalisasikan. Saat ini, seluruh arsip digital yang ada belum diolah dan diidentifikasi secara lengkap. Dari jumlah tersebut, terdapat 3000 arsip yang baru diizinkan untuk diakses dan diolah oleh peneliti. Tujuan penelitian ini yaitu melakukan pengklasifikasian arsip digital Istana Siak dan membuat database dalam bentuk repositori arsip digital Istana Siak. Metode yang digunakan dalam penelitian ini adalah metode observatoris untuk memperoleh data berupa arsip digital. Penelitian ini dilaksanakan di Dinas Perpustakaan dan Arsip Kabupaten Siak Arsip. Hasil penelitiannya, dari jumlah sampel 3000 arsip digital, 149 arsip yang berhasil diolah oleh peneliti. Untuk aplikasi repository, peneliti menggunakan aplikasi repository SETIADI.
\end{abstract}

Kata kunci: Repositori, Arsip Digital, Istana Siak

\begin{abstract}
The digital archive which is the object of this research is the archive of Sultan Syarif Qasim II, who ruled in the period 1915-1946. The entire archive numbered approximately 60 thousand, and most of the archive has been restored and digitized. At present, all existing digital archives have not yet been processed and completely identified. Of these, there are 3000 new archives that are allowed to be accessed and processed by researchers. The purpose of this study is to classify the Siak Istana digital archive and create a database in the form of a Siak Istana digital archive repository. The method used in this study is the observatory method to obtain data in the form of digital archives. The research was carried out at the Siak Archive District Library and Archives Service. The results of his research, from a sample of 3000 digital archives, 149 archives were successfully processed by researchers. For repository applications, researchers use the SETIADI repository application.
\end{abstract}

Keyword: Repositories, Digital Archives, Siak Palace 


\section{PENDAHULUAN}

Kerajaan Siak lahir pada tahun 1723 dengan raja pertama bernama Sultan Abdul Jalil Rahmat Syah yang merupakan anak dari Sultan Mahmud Syah, seorang Raja Johor. Pemerintahan selanjutnya sempat vakum selama 100 tahun karena adanya intrik internal kerajaan, selama itu wilayah Siak diawasi oleh Syahbandar yang bertugas untuk memungut cukai yang berasal dari hasil laut dan hasil hutan. Kala itu, masa pemerintahan berpindah-pindah dari kota Buatan, Mempura, Senapelan-Pekanbaru dan kembali ke Mempura. Pada masa pemerintahan Sultan Ismail periode 1827-1864, pusat pemerintahan berpindah ke kota Siak Sri Inderapura dan menetap di sana hingga jabatannya berakhir. Istana Siak mulai dibangun dengan nama istana Asseraiyah Hasyimiah pada masa pemerintahan Sultan Assayaidis Syarif Hasyim (1889-1908). Kala itu, kerjanaan Siak mengalami kemajuan dalam bidang. Setelah wafatnya Sultan, pada tahun 1915 pemerintahan diturunkan kepada anaknya bernama Sultan Syarif Kasim II dengan masa jabatan berakhir kala proklamasi dikumandangkan dan Kerajaan Siak menjadi bagian dari Republik Indonesia (Siak, 2019).

Kerajaan Siak sudah dalam kondisi mapan secara ekonomi dan adat istiadat ketika periode pemerintahan Sultan Syarif Kasim II (SSKII). Hal ini berkat kerja keras ayahnya, Sultan Syarif Kasim I yang terkenal memiliki pergaulan yang luas dalam bentuk hubungan dagang dengan para pedagang dari luar negeri, seperti dari Eropa dan Timur Tengah. Kala itu, sistem administrasi sangat teratur dan terstruktur. Hal tersebut terlihat dari arsip-arsip peninggalan SSKII yang ditinggalkan dan masih tersimpan baik di istana Siak.

Secara umum, arsip diartikan sebagai berkas penting yang tersimpan dengan sistem tertentu (HS, 2009). Dalam pengertian ini menyebutkan bahwa arsip dapat berwujud dokumen tertulis maupun bentuk lain yang memiliki kaitan dengan seseorang atau organisasi. Sehingga penyimpanan arsip perlu dilakukan dalam rangka menjaga ketersedian informasi penting yang terkandung di dalamnya agar tetap dapat diakses diakses ketika diperlukan.

Saat ini, kondisi arsip-arsip peninggalan SSKII masih tersimpan baik, namun seluruh arsip belum diolah dan didata secara maksimal. Arsip-arsip tersebut dalam bentuk tulisan tangan (manuskrip) dan ketikan. Beberapa usaha telah dilakukan oleh pemerintah Siak agar seluruh arsip terpelihara, antara lain restorasi dan digitalisasi arsip yang telah dilakukan oleh dinas Perpustakaan dan Arsip Kabupaten Siak. Dari sekitar 60 ribu arsip yang ada, baru sebagian saja yang telah direstorasi dan didigitalisasikan. Dari hasil digitalisasi yang sudah dilakukan, belum ada kelajutan agar arsip digital dapat dipublikasikan kepada masyarakat untuk dijadikan bahan penelitian. Salah satu kendala yang dihadapai institusi terebut adalah terbatasnya SDM dan pendanaan.

Dengan berkembangnya teknologi secara pesat, banyak pengelola arsip telah melakukan pengelolaan arsip dengan bantuan teknologi informasi. Bahkan, pasal 32 Undang-undang Kearsipan menyatakan bahwa sarana dan prasarana kearsipan dalam suatu instansi perlu dikembangkan sesuai dengan perkembangan teknologi informasi yang ada (Indonesia, 2009). Pernyataan tersebut mengindikasikanbahwa pengelolaan arsip di seluruh instansi di Indonesia perlu memperhatikan perkembangan teknologi dimasyarakat termasuk arsip Istana Siak.

Melihat kondisi tersebut, maka penulis ingin melakukan penelitian dengan hasil akhir membuatkan repositori arsip digital. Dengan adanya repositori arsip ini, merupakan tahap awal agar institusi dan masyarakat terbantu dalam pencarian data yang bernilai sejarah terkait arsip digital Istana Siak.

Masalah yang diangkat dalam penelitian tentang bagaimana perancangan repositori arsip digital Istana Siak dengan menggunakan apliaksi repository SETIADI. 
Arsip digital adalah "arsip yang diciptakan dan digunakan dalam bentuk elektronik. Arsip digital dapat berasal dari arsip tercetak yang dikonversi menjadi digital atau arsip yang memang "lahir" dalam bentuk digital" (Arsip Digital, 2019).

Hakim (Hakim, 2016) berpendapat dalam pembuatan sistem arsip digital dapat menggunakan berbagai format penyimpanan (.jpg, .pdf, dan video). Hal ini dilakukan agar dapat mengakomodasi pengolahan arsip digital. Terdapat empat cara penyimpanan arsip digital, yaitu:

1. Arsip digital berbasis teks.

2. Arsip digital berbasis gambar.

3. Arsip digital berbasis audio

4. Arsip digital berbasis audio video

Repositori berfungsi sebagai tempat penyimpanan arsip digital suatu lembaga (Karacsony, 2012). Assegaf (Assegaf, 2014) menambahkan bahwa strategi dalam mengembangkan repositori digolongkankan menjadi tiga domain utama, antara lain teknologi pengelolaan basis data, manajemen konten repositori, serta manajemen pengguna.

Berbagai software repositori banyak bermunculan sejak awal perkembangannya yakni sekitar awal tahun 2000-an seperti Eprints, Dspace, Fedora dan lain sebagainya. Dari berbagai software repositori yang dikembangkan, kini telah muncul software repository opensource yang terbaru yang menyesuaikan perkembangan jaman di era sekarang khususnya di Indonesia. Software tersebut adalah Senayan Sistem Elektronik Tesis dan Disertasi (Setiadi). Setiadi merupakan nama software repositori karya dari Dwi Fajar Saputra yang merupakan Pegiat Komunitas Slims Banten. Pada dasarnya Setiadi merupakan hasil pengembangan dari software otomasi Slims Cendana yang dikembangkan khusus untuk pengelolaan repositori. Software ini tidak hanya digunakan untuk mengelola tesis dan disertasi saja seperti namanya, namun software ini dapat digunakan untuk pengelolaan arsip (Asia \& Arfa, 2018).
Kajian tentang arsip di Indonesia masih tergolong jarang dilakukan. Berdasarkan data yang tim dapatkan, saat ini terdapat \pm 387.170 artikel yang terdapat di database Portalgaruda, hanya 0,10\% diantaranya yang mengkaji tentang arsip (Science, 2017). Angka tersebut tentunya masih tergolong sedikit jika dibandingkan dengan jumlah kajian pada bidang lainnya.

Sebagaimana telah disebutkan pada bagian sebelumnya bahwa saat ini telah terjadi pergeseran pengelolaan arsip dari manual kebantuan teknologi. Hal ini dikarenakan pengelolaan arsip secara manual memiliki kelehaman sebagai berikut (Triyono \& Samopa, 2013)

1. Efisiensi waktu. Pengelolaan arsip secara manual memiliki kelemahan dalam efisiensi waktu karena membutuhkan waktu yang lama dalam pencatatan dan distribusi arsip.

2. Duplikasi. Tidak jarang pengelolaan arsip secara manual menimbulkan duplikasi sehingga satu arsip terjadi penggandaan secara berkali-kali. Hal ini tentu saja akan mengurangi ruang penyimpanan dan terjadi pemubadziran.

3. Pencarian kembali. Pencarian kembali arsip secara manual memiliki keterbatasan dikarenakan pengelola harus mencari satu-persatu arsip yang telah tersimpan.

4. Pengawasan. Pengelolaan arsip secara manual memiliki pengawasan yang lemah karena tidak dilengkapi dengan wewenang hak akses . Perancangan sistem kearsipan berbasis teknologi bertujuan untuk mengantisipasi kelemahan-kelemahan yang ada. Oleh karena itu, sistem kearsipan yang baik harus mampu memenuhi beberapa kriteria sebagai berikut (Sutejo, 2004):

a. Tepat informasi. Tepat informasi memiliki artian bahwa informasi yang diminta sama dengan yang ditemukan.

b. Tepat waktu. Sistem informasi kearsipan harus mampu menghemat waktu pengguna dan pengelola arsip. 
c. Tepat guna. Sistem informasi kearsipan harus mampu memiliki daya guna yang tinggi.

d. Tepat sasaran. Sistem informasi kearsipan harus mampu menjangkau sasaran yang ditargetkan.

e. Dilaksanakan dengan biaya serendah mungkin. Meskipun membangun sistem informasi kearsipan terkadang membutuhkan aktu dan biaya, namun dalam praktiknya pembangunan dan pengelolaan sistem informasi kearsipan harus dilakukan dengan mengeluarkan biaya serendah mungkin.

Penelitian relevan terkait objek penelitian belum pernah dilakukan oleh peneliti sebelumnya. Tidak banyak orang membahas spesifik mengenai arsip Kerajaan Siak dalam bentuk repositori, selama ini memang tidak ada peneliti yang melakukannya. Hal ini terjadi karena memang tidak mudah mengakses arsip tersebut secara bebas, perlu perizinan dan birokrasi yang rumit untuk mendapatkannya.

\section{METODE}

Penelitian ini dilakukan melalui beberapa tahap. Pertama adalah tahap observasi. Pada tahap ini, peneliti melakukan pengamatan langsung guna memperleh data kebutuhan repository arsip digital di Istana Siak. Kedua, tahap perancangan sistem informasi yang akan digunakan pada repository arsip digital Istana Siak. Pada tahap ini setelah memperoleh data terkait apa saja yang dibutuhkan, tim peneliti akan membuat repository arsip digital Istana Siak dengan menggunakan aplikasi repository SETIADI. Ketiga, tahap implementasi. Pada tahap ini, repository yang telah dirancang akan diimplementasikan dalam pengelolaan arsip digital Istana Siak.

Pengumpulan data utama dalam penelitian ini dilakukan melalui observasi dan dokumentasi. Selain itu, sebagai data pendukung, penulis juga melakukan penyebaran kuisioner guna menguji penggunaan repository arsip digital yang telah diimplementasikan.

Analisis data dilakukan dengan menggabungkan pendekatan kualitatif dan kuantitatif. Data yang diperoleh melalui teknik observasi dan dokumentasi akan dianalisis secara induktif. Sedangkan data pendukung yang diperoleh melalui hasil angket akan dianalisis dengan melihat distribusi frekuensi jawaban responden.

\section{PEMBAHASAN}

Dokumen yang tersedia saat ini berbentuk file PDF yang merupakan hasil scan arsip koleksi kerajaan Siak. Dari banyaknya dokumen soft file yang tersedia, hanya 3000 file saja yang telah didapatkan oleh peneliti. Sisanya perlu izin khusus dari pihak berwenang yang memiliki tanggung jawab terhadap arsip Siak, seperti dinas Perpustakaan dan Arsip, dinas Kebudayaan, dan pihak Kerajaan Siak itu sendiri. Dari 3000 file yang di dapat, saat ini baru 149 file yang telah diidentifikasi dan dikelompokkan untuk dimasukkan dalam repositori arsip menggunakan eprints. Pengelompokan dibagi menjadi 7 bagian yang terdiri atas kode, nomor surat, tanggal surat, jenis tulisan, subjek surat, ejaan, bahasa, isi / deskripsi surat.

\section{Tabel 1. Jumlah Arsip yang Teridentifikasi}

\begin{tabular}{|l|l|c|}
\hline No & $\begin{array}{c}\text { Kode } \\
\text { BOX }\end{array}$ & $\begin{array}{c}\text { Jumlah Arsip } \\
\text { teridentifikasi dan } \\
\text { di-input }\end{array}$ \\
\hline 1 & K-08 & 149 file \\
\hline
\end{tabular}

\section{Gambar 1. Contoh File Arsip Siak}
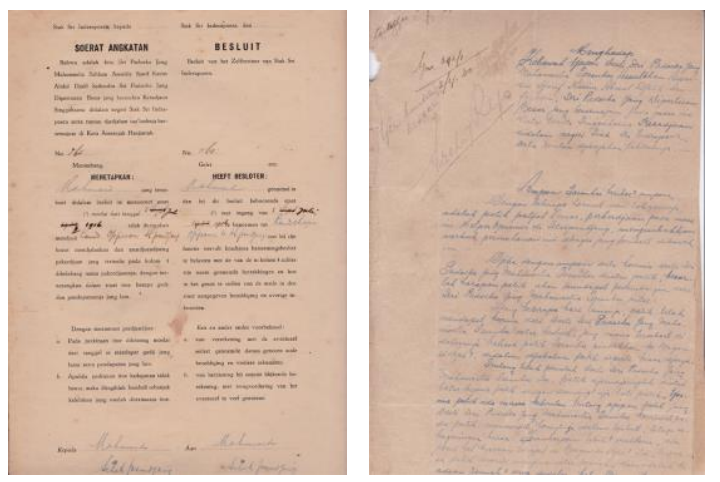

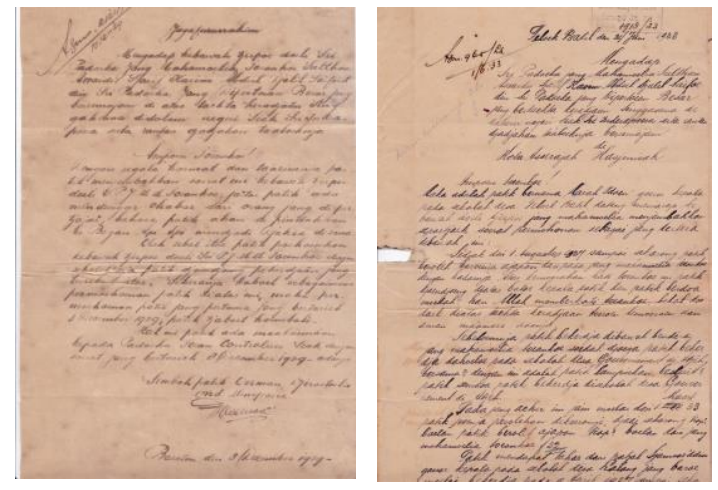

Berikut Tabel Pengelompokan Arsip Siak yang sudah dilakukan oleh peneliti:

\begin{tabular}{|c|c|c|c|c|c|c|c|c|}
\hline No & Kode & $\begin{array}{c}\text { Nomor } \\
\text { Surat }\end{array}$ & $\begin{array}{l}\begin{array}{l}\text { Thuggal } \\
\text { Surat }\end{array} \\
\text { S }\end{array}$ & $\begin{array}{l}\text { Jeuis } \\
\text { Tulisan }\end{array}$ & Subjele Surat & Ejana & Bahasa & Isi/Desleripsi Surat \\
\hline 1 & K08-003 & & 28-Nov-27 & Latin & \begin{tabular}{|l|l|l} 
Surat \\
Keputusan
\end{tabular} & Seow wand. & $\begin{array}{l}\text { Malayu } \\
\text { dan } \\
\text { Belanda }\end{array}$ & 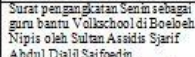 \\
\hline 2 & K08-006 & & 28-Nov-27 & Latin & \begin{tabular}{|l|} 
Surat \\
Keputusan
\end{tabular} & Soew and & $\begin{array}{l}\text { Malayy } \\
\text { dan } \\
\text { Belanda }\end{array}$ & 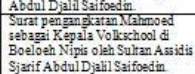 \\
\hline 3 & K08-105 & 280 & $9 / 1 / 1932$ & Latin & \begin{tabular}{|l|} 
Surat \\
Keputusan
\end{tabular} & \begin{tabular}{|l|} 
Soewandi \\
\end{tabular} & $\begin{array}{l}\text { Malayu } \\
\text { dan } \\
\text { Belanda }\end{array}$ & 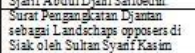 \\
\hline 4 & K08-111 & 261 & $1 / 7 / 1916$ & Latin & \begin{tabular}{|l|} 
Surat \\
Kepurusan
\end{tabular} & Sowmand & $\begin{array}{l}\text { Selaras } \\
\text { Malayyu } \\
\text { dan } \\
\text { Belanda }\end{array}$ & 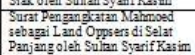 \\
\hline 5 & K08-115 & $25 ?$ & 1/9/1932 & Latin & \begin{tabular}{|l} 
Surat \\
Keputuan
\end{tabular} & \begin{tabular}{|l|} 
Soewand \\
\end{tabular} & $\begin{array}{l}\text { Melalus } \\
\text { Malayyu } \\
\text { dan } \\
\text { Belanda }\end{array}$ & 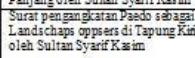 \\
\hline 6 & K08-119 & 254 & $1 / 5 / 1927$ & Latin & \begin{tabular}{|l|} 
Surat \\
Keputuan
\end{tabular} & Soevwand & $\begin{array}{l}\text { Malayy } \\
\text { dany } \\
\text { Belanda }\end{array}$ & 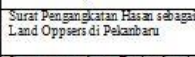 \\
\hline$?$ & K08-122 & 256 & $1 / 9 / 1932$ & Latin & \begin{tabular}{|l|} 
Surat \\
Keputuan
\end{tabular} & \begin{tabular}{|l|} 
Sogwandif \\
\end{tabular} & $\begin{array}{l}\text { Malayu } \\
\text { dan } \\
\text { Belanda }\end{array}$ & 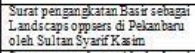 \\
\hline 8 & K08-125 & 263 & $1 / 9 / 1932$ & Latin & $\begin{array}{l}\text { Sura } \\
\text { Kepp }\end{array}$ & Soewandi & $\begin{array}{l}\text { Melayu } \\
\text { dan } \\
\text { Belanda }\end{array}$ & 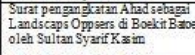 \\
\hline 9 & K08-128 & 268 & $\begin{array}{c}\text { Tidak } \\
\text { Diketahui }\end{array}$ & Latin & & \begin{tabular}{|l|} 
Sogevand \\
\end{tabular} & $\begin{array}{l}\text { Malayu } \\
\text { dan } \\
\text { Belanda }\end{array}$ & 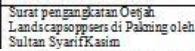 \\
\hline 10 & K08-131 & 267 & $\begin{array}{c}\text { Tidak } \\
\text { Dikethui }\end{array}$ & Latin & $\mid \begin{array}{l}\text { Surat } \\
\text { Keputusan }\end{array}$ & Soewandi & $\begin{array}{l}\text { Nelayu } \\
\text { dan } \\
\text { Belanda }\end{array}$ & 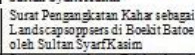 \\
\hline 11 & K08-134 & 271 & $\begin{array}{c}\text { Tidaik } \\
\text { Diketahui }\end{array}$ & Latin & $\begin{array}{l}\text { Surat } \\
\text { Kaputusan }\end{array}$ & Soew and & $\begin{array}{l}\text { Malayyu } \\
\text { dany } \\
\text { Belanda }\end{array}$ & 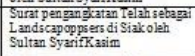 \\
\hline 12 & K08-139 & & $1 / 9 / 1932$ & Latin & $\begin{array}{l}\text { Surat } \\
\text { Keputusan }\end{array}$ & Soewwand & $\begin{array}{l}\begin{array}{c}\text { Melayy } \\
\text { dan } \\
\text { Belanda }\end{array} \\
\end{array}$ & 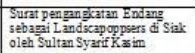 \\
\hline 13 & K0S-142 & 278 & 1/9/1932 & Latin & \begin{tabular}{|l} 
Surat \\
Keputusan
\end{tabular} & Solwand & $\begin{array}{l}\text { Melasul } \\
\text { dany } \\
\text { Belanda }\end{array}$ & 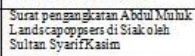 \\
\hline 14 & K08-144 & 269 & Diketak & Latin & $\begin{array}{l}\text { Surat } \\
\text { Keput }\end{array}$ & \begin{tabular}{|l|} 
Sotwandif \\
\end{tabular} & \begin{tabular}{|l}
$\begin{array}{l}\text { Melayu } \\
\text { dan } \\
\text { Belanda }\end{array}$ \\
\end{tabular} & 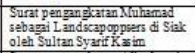 \\
\hline 15 & K08-147 & & 1 Naret 1925 & Latin & $\begin{array}{l}\text { Surat } \\
\text { Keputa }\end{array}$ & Dew and & $\begin{array}{l}\begin{array}{l}\text { Melayu } \\
\text { dan } \\
\text { Belanda }\end{array} \\
\end{array}$ & 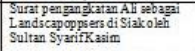 \\
\hline 16 & K08-150 & 338 & 1 Naret 1930 & Latin & $\begin{array}{l}\text { Surat } \\
\text { Repurusan }\end{array}$ & Somwand & $\begin{array}{l}\text { Melasyu } \\
\text { dany } \\
\text { Belanda }\end{array}$ & 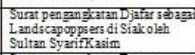 \\
\hline 17 & K08-154 & 317 & $\begin{array}{c}\text { Tidak } \\
\text { Diketahui }\end{array}$ & Latin & \begin{tabular}{|l} 
Surat \\
Keputr.
\end{tabular} & ew & $\begin{array}{l}\text { Melayu } \\
\text { dinn } \\
\text { Belanda }\end{array}$ & 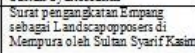 \\
\hline 18 & K08-162 & 316 & 1-Sep-32 32 & Latin & \begin{tabular}{|l} 
Surat \\
Keputusan
\end{tabular} & Somwand & $\begin{array}{l}\text { Melasyu } \\
\text { dany } \\
\text { Belanda }\end{array}$ & 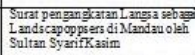 \\
\hline 19 & K08-166 & 279 & 1-Sep-32 32 & Latin & \begin{tabular}{|l} 
Surat \\
Keputusan
\end{tabular} & Soewand & $\begin{array}{l}\text { Melasuy } \\
\text { dany } \\
\text { Belanda }\end{array}$ & $\begin{array}{l}\text { Surat penganglatan Bidin sebagar } \\
\text { Landschaps opposers di Siak oleh } \\
\text { Sultan SyarifKasima }\end{array}$ \\
\hline
\end{tabular}

\begin{tabular}{|c|c|c|c|c|c|c|c|c|}
\hline 20 & K08-168 & 340 & $\begin{array}{l}\text { Tidalk } \\
\text { Dikathui }\end{array}$ & Ketik & \begin{tabular}{|l} 
Surat \\
Keputusan
\end{tabular} & Soewandi & Melayu $\mid$ & 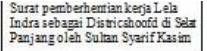 \\
\hline 21 & K08-169 & 3830 & 9 Juli 1932 & $\begin{array}{c}\text { Katrikdan } \\
\text { Latin } \\
\end{array}$ & & & Belanda & \\
\hline 22 & K08-171 & 87 & 18 Mee 1832 & Latin & $\begin{array}{l}\text { Surat } \\
\text { Keputusan }\end{array}$ & Soewand & \begin{tabular}{|l|} 
Malayu \\
dan \\
Belanda
\end{tabular} & $\begin{array}{l}\text { Surat pemininahan dari Pekanhary } \\
\text { ke Bukit Batu }\end{array}$ \\
\hline 23 & K08-215 & 168 & $\begin{array}{c}\text { Tidal } \\
\text { Diketahui }\end{array}$ & Latin & $\begin{array}{l}\text { Surat } \\
\text { Kaputusan }\end{array}$ & Soswandi & \begin{tabular}{|l|l|} 
Nelaytu \\
Belanda
\end{tabular} & $\begin{array}{l}\text { Surat penganglatan Moharmad } \\
\text { Syarif sebagan Rulpschujin di } \\
\text { Bagan Siapi-api }\end{array}$ \\
\hline 24 & K08-219 & 21 Geheir & $20-\operatorname{Sep}-29$ & Ketik & \begin{tabular}{|l|} 
Surat \\
Pemphonan \\
Berhenti
\end{tabular} & Soeswand & Melayu & 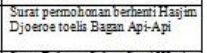 \\
\hline 25 & $\mathrm{~K} 08-223$ & & $\begin{array}{l}\text { Tidak } \\
\text { Diketahui }\end{array}$ & Latin & $\begin{array}{l}\text { Surt } \\
\text { Penerimaan } \\
\text { Permohonan } \\
\text { Berhenti }\end{array}$ & Soevand & Melayu & 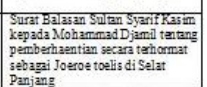 \\
\hline 26 & K108-262 & $573 / 18$ & $\begin{array}{l}{ }^{1} \text { A poustus } \\
1927\end{array}$ & $\begin{array}{c}\text { Latin dan } \\
\text { Ketili }\end{array}$ & \begin{tabular}{l|} 
Surat \\
pemberitahuan
\end{tabular} & Soswand & Melayu & 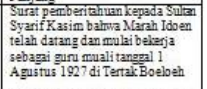 \\
\hline${ }^{27}$ & K08-300 & & $\begin{array}{c}16 \text { Agustus } \\
1933\end{array}$ & Latin & \begin{tabular}{|l|} 
Surat \\
Keputusan
\end{tabular} & Soswand & \begin{tabular}{|l|} 
Melayyu \\
dan \\
Belanda \\
\end{tabular} & 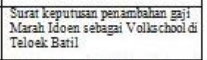 \\
\hline 28 & K08-304 & 190 & \begin{tabular}{|c|c|}
16 Agustus \\
1933
\end{tabular} & Latin & \begin{tabular}{|l|} 
Surat \\
Kepurusan
\end{tabular} & Soowand & \begin{tabular}{|l|} 
Melayuu \\
dan \\
Belanda \\
\end{tabular} & \begin{tabular}{|l|}
$\begin{array}{l}\text { Surat pen gan gatan Narahidoent } \\
\text { sebagar Schoolhoofd di Teloek } \\
\text { Batil }\end{array}$ \\
\end{tabular} \\
\hline 29 & K08-313 & 237 & $\begin{array}{c}\text { Tidak } \\
\text { Dikethui } \\
\end{array}$ & Latin & \begin{tabular}{|l} 
Surat \\
Kepurusan
\end{tabular} & Soew and & \begin{tabular}{|l|} 
Melayus \\
dan \\
Belanda
\end{tabular} & 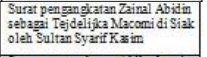 \\
\hline 30 & K08-107 & 271 & 1-Sepp-32 & Latin & \begin{tabular}{|l|} 
Surat \\
Keputusan
\end{tabular} & Soewand & \begin{tabular}{|l|} 
Malayu \\
dan \\
Belanda
\end{tabular} & 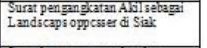 \\
\hline 31 & K09-002 & & 24 Juni 1935 & Ketik & \begin{tabular}{|l|l} 
Surata \\
Keputrusan
\end{tabular} & Soew andi? & \begin{tabular}{|l|}
$\substack{\text { Malayu } \\
\text { danl } \\
\text { Belanda }}$ \\
Band
\end{tabular} & 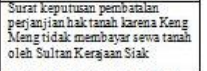 \\
\hline 32 & K09-003 & 147 & 15 Juli 1932 & Latin & \begin{tabular}{|l|} 
Surat \\
Penganglatan
\end{tabular} & Soeswand & \begin{tabular}{l|}
$\begin{array}{l}\text { Melalayu } \\
\text { dan } \\
\text { Belanda }\end{array}$ \\
\end{tabular} & 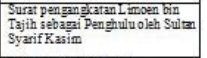 \\
\hline 33 & K09-007 & 110 & 24 Nei 1930 & Ketik & \begin{tabular}{|l|} 
Surat \\
Keputusan
\end{tabular} & Soewandid & \begin{tabular}{|l|} 
Malyu \\
dant \\
Belanda
\end{tabular} & 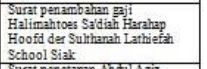 \\
\hline 34 & K09-008 & 240 & \begin{tabular}{|c|c}
$\begin{array}{c}\text { Tidakk } \\
\text { Diketahui }\end{array}$ & K \\
\end{tabular} & $\begin{array}{c}\text { Ketikidan } \\
\text { Latin } \\
\end{array}$ & Surat keputuan & & \begin{tabular}{|l|} 
Malayu \\
dan \\
Belanda \\
\end{tabular} & 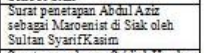 \\
\hline 35 & K09-011 & $390 / \mathrm{LK}$ & 5 Mei 1930 & Ketili & $\begin{array}{l}\text { Surat } \\
\text { permohonan }\end{array}$ & $\begin{array}{l}\text { Soewandi/2 } \\
2\end{array}$ & Melayu & 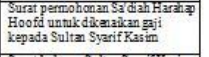 \\
\hline 36 & K09-012 & $739 \mathrm{~L} \mathrm{~K}$ & 26 Mei 1930 & Ketik & Surat balasan & Soswand? & Melayu & 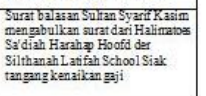 \\
\hline 37 & K09-013 & $705 \mathrm{LLK}$ & 24 Mei 1930 & Ketik & Surat balasan & | Soew andi & |Melayu & $\begin{array}{l}\text { Surat balasan den Controleur van } \\
\text { Siekk kepada Sultan Syarif Kasm } \\
\text { terkait afschriften verhoogmg } \\
\text { besluit Halimatoes Sa'diah Harahap }\end{array}$ \\
\hline 38 & K09-016 & 57 & $\begin{array}{c}\text { Tidak } \\
\text { Dikethai }\end{array}$ & $\begin{array}{c}\text { Latin dan } \\
\text { Ketalk }\end{array}$ & \begin{tabular}{|l|}
$\begin{array}{l}\text { Surat } \\
\text { Keputusan }\end{array}$ \\
\end{tabular} & Soewandi & \begin{tabular}{|l|l|} 
Melayu \\
dan \\
Belanda
\end{tabular} & $\begin{array}{l}\text { Surat pengangkatan Halimatoes } \\
\text { Sa'diah Harahap sebagai Goeroe } \\
\text { keppla dari sekolah anak-anak } \\
\text { perempoean di Siak oleh Sultan } \\
\text { Syarif Kasim }\end{array}$ \\
\hline 39 & K09-019 & & 2 Juli 1929 & Ketik & $\begin{array}{l}\begin{array}{l}\text { Surat } \\
\text { permohonan }\end{array} \\
\end{array}$ & \begin{tabular}{|l|} 
Soevwandi \\
\end{tabular} & Melayu & $\begin{array}{l}\text { Surat permohonan Sultan Syarif } \\
\text { Kasim tetang permintan Blanko } \\
\text { susarktkepada den Controleur van } \\
\text { Sialk }\end{array}$ \\
\hline 40 & 476 & $\begin{array}{l}\text { stempel } \\
\text { pos dan } \\
\text { kepapla } \\
\text { surat } \\
\end{array}$ & 8.20.371.2569 & latim & kepala surat & soewandi & Melayu & $\begin{array}{l}\text { amplop surat untuk S.P.J.ouM } \\
\text { Toeankoe Jang dipertouan Soeltan } \\
\text { Siak }\end{array}$ \\
\hline 41 & 499 & & & $\begin{array}{l}\text { latin } \\
\text { thlisan } \\
\text { tangan }\end{array}$ & is surat & soewandi & Melayu & $\begin{array}{l}\text { isis suratS. P. J.ouM Toeamkoe Jang } \\
\text { dipettouan Soeltan Siak }\end{array}$ \\
\hline 42 & 500 & & & $\begin{array}{l}\text { latim } \\
\text { tulisan } \\
\text { tangen }\end{array}$ & surathalaman 4 & soevandi & Melayu & kenakkan gaji \\
\hline 43 & 503 & & & $\begin{array}{l}\text { latim } \\
\text { tulisan } \\
\text { tangan } \\
\text { than }\end{array}$ & isi surat & soewandi & Belanda & lanjutan surat \\
\hline 44 & 504 & & & $\begin{array}{l}\text { latim } \\
\text { tulisan } \\
\text { tangen } \\
\text { tang }\end{array}$ & isisurat & soevwandi & Belanda & lanjutan surat \\
\hline 45 & 523 & & & 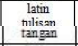 & daftar gaji & soevandi & Belanda & daftar gaji pegawai \\
\hline 46 & 524 & & & 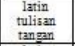 & daftar $m_{j j} i$ & soewandi & Melayu & daftar gaji lama pegarwai \\
\hline 47 & 525 & & & 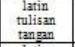 & daffar gaji & soewandi & Nelayu & daftar gaji barn pegawai \\
\hline 48 & 526 & & & $\begin{array}{l}\text { latin } \\
\text { tulisen } \\
\text { tangen } \\
\text { tangen }\end{array}$ & daftar gaji 1 & soewandi & Nelayu & daftar mji baru pegawai \\
\hline 49 & 626 & & 8.215102710 & 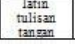 & daftar gaji & soew andi & \begin{tabular}{|l|l} 
Melayu \\
Belanda
\end{tabular} & \\
\hline
\end{tabular}

Dari pengelompokan repository yang sudah dilakukan, tahapan berikutnya adalah proses penginputan ke dalam aplikasi repository Setiadi. Berikut ini cara input arsip pada repository Setiadi:

* Menambah data arsip baru, klik Add New ETD. Maka akan muncul layar seperti di bawah ini: 
Gambar 1: Form untuk menambahkan data bibliografi arsip dilengkapi tooltip

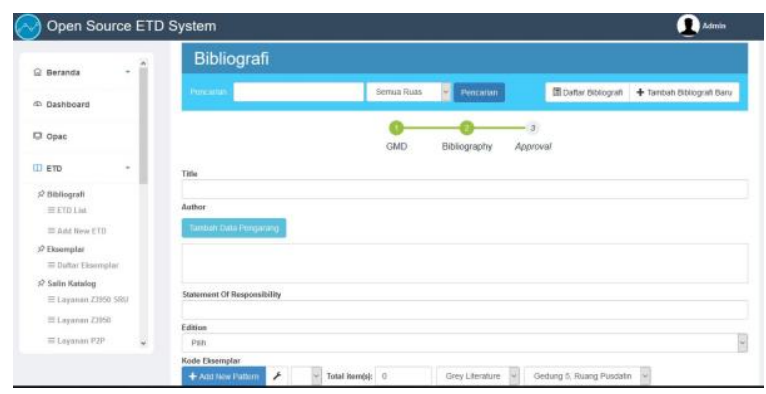

- Metadata yang harus diisikan adalah:

1.GMD: General Material Designation

2.Title: Kode Arsip

3.Author: Kepengarangan

4.Kode Eksemplar: Kode Arsip

5.Specific Detail Info: Berisi informasi khusus, misalnya $1 \mathrm{Lbr}$

6.Lembar Pengesahan: Tanggal input data

7.Publisher: Nama penerbit/Institusi pembuat dokumen

8.Publish Year: Tahun Pembuatan Dokumen

9.Publishing Place: Tempat Pembuatan Dokumen

10. Collation: Deskripsi arsip, misalnya Latin; Soewandi, Tulisan tangan

11. File Lampiran: File arsip hasil scan

12. Subjek: Perihal arsip/topik

13. Abstrak: Catatan penting/deskripsi singkat berkaitan dengan arsip yang di-input

14. Klasifikasi : Nomor kelas, berisi Kode Arsip

15. No. Panggil : Nomor kelas, berisi Kode Arsip

* Setelah data diisikan, klik Approval. Jika berhasil maka sistem akan memunculkan informasi bahwa data, file dan gambar telah sukses di simpan. Layar tidak akan berganti, namun akan bertambah. Tambahannya adalah hasil generate item sesuai dengan yang diisikan. Letaknya di bawah Specific Detail Info.
Gambar 2: Tampilan Hasil Pembuatan Item

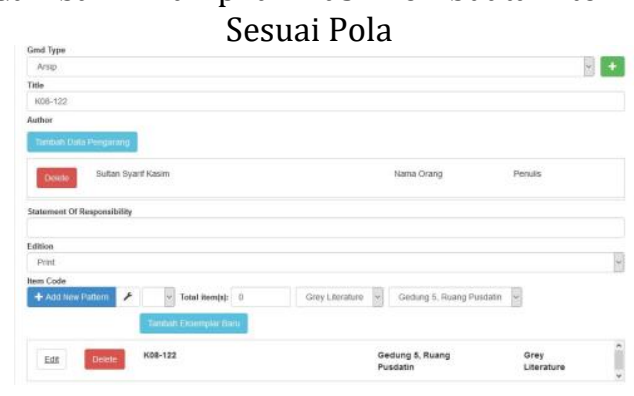

* Selanjutnya Klik Simpan. Data, gambar dan file sudah dapat diakses melalui OPAC/Katalog (SLiMS, 2018). Seperti pada gambar di bawah ini:

Gambar 3: Tampilan OPAC/Katalog Repository SETIADI

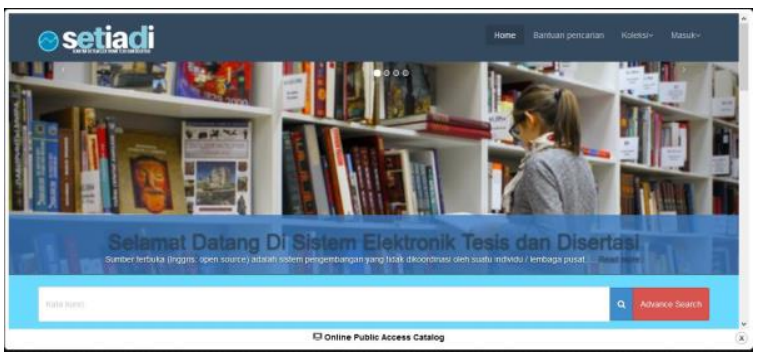

Gambar 4: Tampilan Info File yang telah diinput

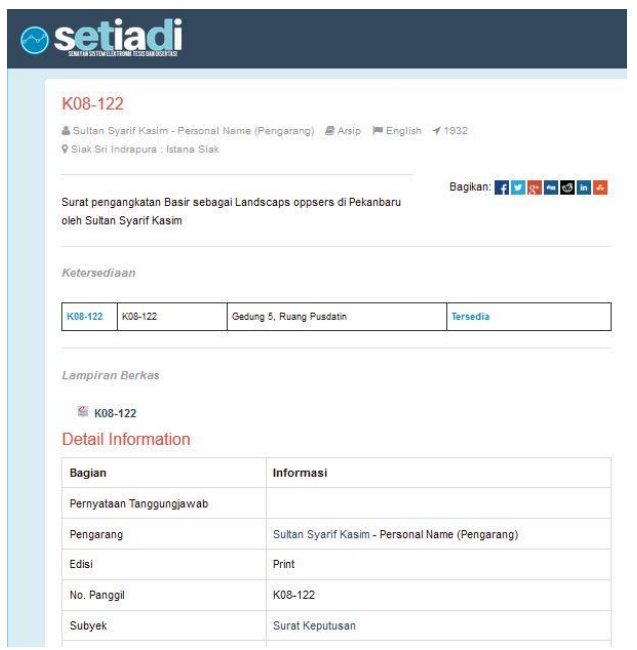




\section{SIMPULAN}

Pendataan awal terhadap 49 file yang dibagi menjadi 8 bagian antara lain, kode, nomor surat, tanggal surat, jenis surat, jenis tulisan, subjek surat, ejaan, bahasa, dan isi/deskripsi surat. Tahap selanjutnya, data yang telah tersusun diinput dalam dalam aplikasi repository SETIADI.

\section{DAFTAR PUSTAKA}

Arsip Digital. (2019, November 10).

Retrieved November 10, 2019, from http://arsip.ui.ac.id: http://arsip.ui.ac.id/arsip-digital

Asia, E., \& Arfa, M. (2018). Efektifitas Penggunaan Repository Setiadi di Fakultas Hukum Universitas Negeri Semarang. Jurnal Humanus , 10-17.

Assegaf, S. (2014). Mengembangkan Repositories dalam Knowledge Management. Jurnal Ilmiah Media Processor , 167-71.

Gunaidi, A., Nurhadryani, Y., \& Muljono, P. (2018). Pengembangan Sistem Repositori Arsip Digital pada Dinas Kependudukan dan Pencatatan Sipil dalam Mendukung Smart Governance. BACA: Jurnal Dokumentasi dan Informasi , 101111.

Hakim, H. A. (2016). Omeka: Aplikasi Pengelola Arsip Digital dalam Berbagai. Khazanah: Jurnal Pengembangan Kearsipan , 23-35.

HS, L. (2009). Kamus Kepustakawanan Indonesia. Yogyakarta: Yayasan Obor Indonesia.
Indonesia, K. H. (2009). Undang-undang Republik Indonesia Nomor 43 Tahun 2009 tentang Kearsipan. Retrieved November 10, 2019, from https://www.anri.go.id: https://www.anri.go.id/assets/dow nload/87Nomor-43-Tahun-2009Tentang-Kearsipan.pdf

Karacsony, G. (2012). HUNOR : The Collaboration of Hungarian Open Access. Procedia-Social and Behavioral Sciences (pp. 57-61). Elsevier.

Science, I. o. (2017). Indonesian Publication Index. Retrieved november 10, 2019, from http://portalgaruda.org: http://portalgaruda.org

Siak, D. K. (2019, November 10). Sejarah Siak. Retrieved November 10, 2019, from http://siakkab.go.id:

http://siakkab.go.id/sejarah-siak/

SLiMS, T. (2018, Juli 20). Dokuemntasi SLiMS Berdasar SLiMS-7 Cencana v.1. Retrieved November 9, 2019, from https://slims.web.id/: https://slims.web.id/download/doc s/s7-cendana-doc-id-v.1.pdf

Triyono, T., \& Samopa, F. (2013). Pembuatan Sistem Informasi Penatausahaan Surat dan Arsip Berbasis Web Studi Kasus Kantor Pelayanan Perbendaharaan Negara Bengkulu. Jurnal Teknik Pomits , 346349. 